\title{
Grafting of Polymers with Controlled Molecular Weight onto Carbon Black Surface
}

\author{
Sachio YoshiKawa and Norio TsuboKawa*, \\ Graduate School of Science and Technology, Niigata University 8050 Ikarashi 2-nocho, Niigata 950-21, Japan. \\ * Department of Chemistry and Chemical Engineering, Faculty of Engineering, \\ Niigata University, 8050 Ikarashi 2-nocho, Niigata 950-21, Japan.
}

(Received August 8, 1995)

\begin{abstract}
To graft polymers with controlled molecular weight and narrow molecular weight distribution, the grafting of polymers onto carbon black surface by the termination of living polymer cation with nucleophilic groups, such as amino groups and sodium phenolate and sodium carboxylate groups, introduced onto the surface was investigated. The introduction of amino groups onto the carbon black surface was achieved by the reduction of nitro groups introduced by the nitration of surface aromatic rings. Sodium phenolate and sodium carboxylate groups were introduced onto the surface by the treatment of surface carboxyl and phenolic hydroxyl groups with sodium hydroxide. These nucleophilic groups on carbon black readily reacted with living poly(isobutyl vinyl ether) (poly(IBVE)) cation, and poly(IBVE) with controlled molecular weight and narrow molecular weight distribution was grafted onto the surface. By the termination of living poly(2-methyl-2-oxazoline) (poly(MeOZO)) cation with these nucleophilic groups on carbon black, poly(MeOZO) was also grafted onto the surface. The mole number of grafted polymer chain on carbon black surface decreased with increasing molecular weight of the living polymer, because the steric hindrance of carbon black surface increased with increasing molecular weight of living polymer. The dispersibility of carbon black was remarkably improved by the grafting of polymers onto the surface.

KEY WORDS Carbon Black / Surface Grafting of Polymer / Living Polymer Cation / Termination /

Nucleophilic Groups / Poly(isobutyl vinyl ether) / Poly(2-methyl-2-oxazoline) /
\end{abstract}

To improve the surface properties of carbon black, the surface grafting of polymers is effective. Polymer-grafted carbon black can be dispersed easily in organic solvents, polymer resins, and rubbers. Accordingly, the grafting of polymers onto carbon black surface is of industrial importance.

We reported the grafting of various polymers onto carbon black surface by the polymerization of monomers initiated by initiating groups previously introduced onto the surface..$^{1-3}$ For instance, we achieved the anionic, cationic, and radical graft polymerization of various monomers initiated by potassium carboxylate, ${ }^{4,5}$ acyli$u^{6}{ }^{6}$ or benzylium perchlorate, ${ }^{7}$ and peroxyester ${ }^{8}$ or azo $^{9}$ groups introduced onto carbon black, respectively. In the graft polymerization, the corresponding polymers are effectively grafted onto the surface by propagation of the grafted polymers from the surface. Control of molecular weight and number of grafted chain on the surface are difficult, except for the radical grafting system. ${ }^{10}$

We demonstrated that various polymers with well defined molecular weight and structure can be grafted onto carbon black surface by the reaction of surface reactive groups with hydroxyl- or amino-capped polymers. ${ }^{11}$ Donnet et al. reported the grafting of polystyrene by the termination of living polymer anion with surface ester groups on silica. ${ }^{12,13}$ Recently, we reported the grafting of polymers with controlled molecular weight and narrow molecular weight distribution onto ultrafine silica by the termination of living polymer cation with surface amino groups on the surface. ${ }^{14}$

The grafting of polymers with controlled molecular weight and molecular weight distribution onto carbon black is required for the preparation of high-performance carbon black/polymer nano-composite and functionaliza-

\footnotetext{
$\dagger$ To whom correspondence should be addressed.
}

tion of carbon black by the surface grafting of polymers, such as bioactive, photosensitive, and electroconductive polymers. There are a few reports dealing with the effects of molecular weight of grafted chain on the dispersibility of polymer-grafted carbon black.

In the present paper, to graft polymers with controlled molecular weight and narrow molecular weight distribution onto carbon black surface, the grafting of polymers onto carbon black surface by termination of living polymer cation with nucleophilic groups, such as amino groups and sodium phenolate and carboxylate groups, introduced onto the surface (eq 1 and 2) is discussed. The effects of molecular weight of grafted polymer on the stability of polymer-grafted carbon black dispersion in organic solvents are also discussed.

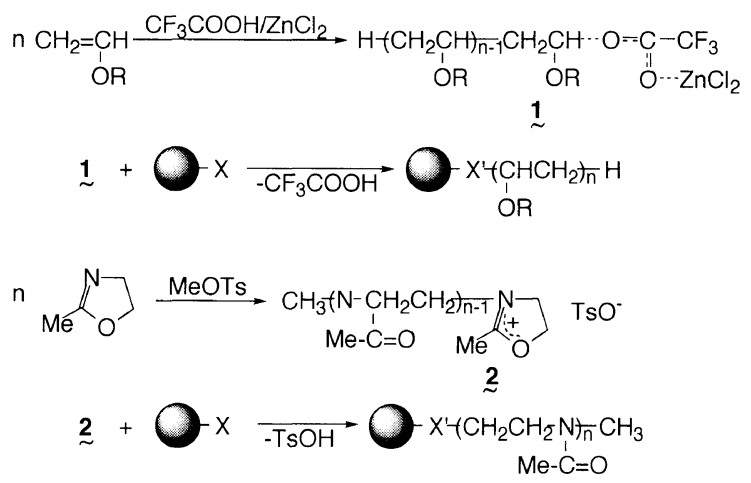

EXPERIMENTAL

Materials and Reagents

Channel blacks Neospectra II (Columbian Carbon Co.) and FW 200 (Degussa A.G.) were used without further purification. Furnace blacks Philblack $O$ and Philblack I (Phillips Petroleum Co.) were extracted with 
Table I. Properties of carbon blacks

\begin{tabular}{|c|c|c|c|c|c|}
\hline \multirow{2}{*}{$\mathrm{CB}$} & Surface area & Particle size & $\mathrm{OH}$ & $\mathrm{COOH}$ & $\mathrm{C}=\mathrm{O}$ \\
\hline & $\mathrm{m}^{2} \mathrm{~g}^{-1}$ & $\mathrm{~nm}$ & $\mathrm{mmolg}^{-1}$ & $\mathrm{mmolg}^{-1}$ & $\mathrm{mmolg}^{-1}$ \\
\hline FW $200^{a}$ & 460 & 13 & 0.10 & 0.61 & 1.42 \\
\hline Philblack $\mathrm{O}^{\mathrm{b}}$ & 79.6 & 29.4 & 0.02 & 0 & 0.18 \\
\hline Philblack $\mathrm{I}^{\mathrm{b}}$ & 116.8 & 28.6 & 0.05 & 0 & 0.23 \\
\hline
\end{tabular}

${ }^{\mathrm{a}}$ Channel black. ${ }^{\mathrm{b}}$ Furnace black.

chloroform on a Soxhlet apparatus to remove resinous substances. These carbon blacks were dried in vacuo at $110^{\circ} \mathrm{C}$ for $48 \mathrm{~h}$ before use. The properties of the carbon blacks (BET specific surface area, particle size, and the content of carboxyl $(\mathrm{COOH})$, phenolic hydroxyl $(\mathrm{OH})$, and quinonic oxygen $(\mathrm{C}=\mathrm{O})$ groups) are shown in Table I.

Isobutyl vinyl ether (IBVE) was washed with 5\% aqueous alkali and water, dried over potassium hydroxide, refluxed over sodium, and distilled just before use. 2Methyl-2-oxazoline (MeOZO) obtained from Aldrich Chemical Co. was dried over calcium hydride and distilled just before use.

Trifluoroacetic acid and zinc chloride (1.0 M solution in diethylether) were obtained from Aldrich Chemical Co., which were diluted with toluene $\left(0.20 \mathrm{~mol} \mathrm{~L}^{-1}\right)$ and stored in ampules at $-30^{\circ} \mathrm{C}$. Methyl $p$-toluenesulfonate (MeOTs) was obtained from Tokyo Kasei Kogyo Co., Ltd. and used without further purification. Toluene was washed with concentrated sulfuric acid, aqueous alkali and pure water, dried over calcium chloride, refluxed over sodium, and distilled. Acetonitrile was dried over calcium hydride, distilled over diphosphorous pentaoxide and distilled over calcium hydride.

\section{Introduction of Sodium Phenolate and Sodium Carbox- ylate Groups onto Carbon Black Surface}

Sodium phenolate and sodium carboxylate groups were introduced onto the carbon black surface by the neutralization of phenolic hydroxyl and carboxyl groups on the surface with sodium hydroxide. ${ }^{15}$ Into a $100 \mathrm{~mL}$ flask, $3.0 \mathrm{~g}$ of carbon black and $80 \mathrm{~mL}$ of $10 \%$ methanol solution of sodium hydroxide were charged. The mixture was stirred for $24 \mathrm{~h}$ with a magnetic stirrer at $30^{\circ} \mathrm{C}$. After the reaction, the resulting carbon black was filtered and repeatedly washed with absolute methanol until the filtrate was neutral. The resulting carbon black was dried in vacuo at room temperature. The carbon black having sodium phenolate and sodium carboxylate groups was abbreviated as $\mathrm{CB}-\mathrm{ONa}$.

\section{Introduction of Amino Groups onto Carbon Black Surface}

The introduction of amino groups onto carbon black was achieved by the reduction of nitrated carbon black. The nitration of polycondensed aromatic rings of carbon black was carried out as follows. ${ }^{16}$ To a suspension of $3.0 \mathrm{~g}$ of carbon black in $120 \mathrm{~mL}$ of acetic anhydride, $30 \mathrm{~mL}$ of fuming nitric acid were added under stirring with a magnetic stirrer at below $5^{\circ} \mathrm{C}$ for $5 \mathrm{~h}$ and then at room temperature for $5 \mathrm{~h}$. After the reaction, the contents of the flask were poured into $1 \mathrm{~L}$ of ice cooled water. The supernatant solution was removed by decantation and the carbon black precipitated was washed with distilled water until the filtrate was neutral.

Reduction of the nitro groups on carbon black was carried out as follows. Into a $200 \mathrm{~mL}$ flask that contained $3.0 \mathrm{~g}$ of nitrated carbon black, $12 \mathrm{~mL}$ of $30 \%$ ammonia water, $50 \mathrm{~mL}$ of distilled water and $80 \mathrm{~mL}$ of $15 \%$ sodium hydrosulfite aqueous solution were added. The reaction mixture was stirred with a magnetic stirrer at room temperature for $24 \mathrm{~h}$. After the reaction, the carbon black was filtered and washed with distilled water until the filtrate was neutral. The carbon black having an amino group was abbreviated as $\mathrm{CB}-\mathrm{NH}_{2}$. The amount of amino groups introduced onto the carbon black surface was determined by titration with hydrochloric acid. ${ }^{16,17}$

\section{Living Cationic Polymerization of IBVE and $\mathrm{MeOZO}$}

The preparation of living poly(IBVE) cation was carried out by the cationic polymerization of IBVE using $\mathrm{CF}_{3} \mathrm{COOH} / \mathrm{ZnCl}_{2}$ initiating system according to the method of Higashimura and Sawamoto. ${ }^{18,19}$ The polymerization was carried out in a $100 \mathrm{~mL}$ flask equipped with a three-way stopcock under dry nitrogen. The polymerization was initiated by adding $1.0 \mathrm{~mL}$ of $\mathrm{ZnCl}_{2}$ solution $\left(0.10 \mathrm{~mol} \mathrm{~L}^{-1}\right.$ in toluene) into $8.0 \mathrm{~mL}$ of IBVE solution $\left(0.50 \mathrm{~mol} \mathrm{~L}^{-1}\right.$ in toluene $)$ containing $1.0 \mathrm{~mL}$ of $\mathrm{CF}_{3} \mathrm{COOH}$ solution $\left(0.08 \mathrm{~mol} \mathrm{~L}^{-1}\right.$ in toluene $)$. The polymerization was conducted at $0^{\circ} \mathrm{C}$ for $1 \mathrm{~h}$, and conversion was determined from residual IBVE concentration by gas chromatography reached $100 \%$.

The living poly(MeOZO) cation was prepared by the cationic ring-opening polymerization of $\mathrm{MeOZO}$ by use of MeOTs as a catalyst according to the method of Saegusa et $a .^{20,21}$ Into a $100 \mathrm{~mL}$ flask, equipped with a three-way stopcock, containing $120 \mathrm{mmol}$ of $\mathrm{MeOZO}$ and $15.0 \mathrm{~mL}$ of acetonitrile, $6.6 \mathrm{mmol}$ of MeOTs were added via a syringe. The polymerization was conducted at $80^{\circ} \mathrm{C}$ for $20 \mathrm{~h}$ under dry nitrogen and at that time, the conversion determined from residual $\mathrm{MeOZO}$ concentration was $100 \%$.

\section{Quenching of the Living Polymer Cation}

The quenching of living poly(IBVE) and poly(MeOZO) was achieved by the addition of $5.0 \mathrm{~mL}$ of $10 \%$ ammonical methanol to the polymerization mixture after $1 \mathrm{~h}$ and $4 \mathrm{~h}$, respectively, at which the conversions of IBVE and $\mathrm{MeOZO}$ were $100 \% .^{14}$

\section{Reaction of Carbon Black with Living Polymer Cation}

Into $100 \mathrm{~mL}$ flask that contained $0.01 \mathrm{~g}$ of CB- $\mathrm{NH}_{2}$ (or $\mathrm{CB}-\mathrm{ONa}), 10 \mathrm{~mL}$ toluene solution $\left(8.0 \times 10^{-5} \mathrm{~mol} \mathrm{~L}^{-1}\right)$ of living poly(IBVE) were added in a grove box under dry nitrogen. The flask was sealed and the mixture was 
stirred with a magnetic stirrer at $0^{\circ} \mathrm{C}$. After a definite time, the reaction was termination by the addition of methanol. For the grafting reaction of poly(MeOZO), $26.0 \mathrm{~mL}$ of polymer solution $\left(0.25 \mathrm{~mol} \mathrm{~L}^{-1}\right.$ in acetonitrile) were allowed to react with $0.01 \mathrm{~g}$ of carbon black.

\section{Percentage of Grafting}

The carbon black obtained from the above reactions was dispersed in toluene and the system was centrifuged at $1.0 \times 10^{4} \mathrm{rpm}$. The carbon black precipitated was dispersed again in toluene and centrifuged. These procedures were repeated until no more polymer could be detected in the supernatant solution. The percentage of grafting was,

$$
\text { Grafting }(\%)=\frac{\text { Polymer grafted }(\mathrm{g})}{\text { Carbon black used }(\mathrm{g})} \times 100
$$

The amount of polymer grafted onto the carbon black surface was determined by weight loss when polymergrafted carbon black was heated at $500^{\circ} \mathrm{C}$ by a thermal analyzer.

\section{Dispersibility of Polymer-Grafted Carbon Black}

Polymer-grafted carbon black was dispersed in a good solvent of grafted chains and allowed to stand at room temperature. The stability of the polymer-grafted carbon black dispersion in solvents was estimated from the content of carbon black in the dispersion after standing. The detailed procedures were described in the previous paper. ${ }^{9}$

\section{Determination of Molecular Weight}

The molecular weight and molecular weight distribution of poly(IBVE) and poly(MeOZO) were estimated by GPC using polystyrene standards: for GPC, a Hitachi 655A-11 Liquid Chromatography was used.

\section{RESULTS AND DISCUSSION}

Introduction of Nucleophilic Groups onto Carbon Black

The termination of living poly(IBVE) cation with nucleophiles having functional groups, end-capped poly(IBVE) has been conducted. ${ }^{22-24}$ Therefore, the grafting of poly(IBVE) onto carbon black surface by the termination of living poly(IBVE) with surface nucleophilic groups on carbon black, $\mathrm{CB}-\mathrm{ONa}$ and $\mathrm{CB}-\mathrm{NH}_{2}$, was investigated (eq 1).

The preparation of $\mathrm{CB}-\mathrm{ONa}$ was achieved by treatment of phenolic hydroxyl and carboxyl groups on carbon black with sodium hydroxide in methanol. ${ }^{15}$ The introduction of amino groups onto carbon black surface was achieved by the reduction of nitrated carbon black. ${ }^{16}$

The amounts of nucleophilic groups introduced onto the carbon black surface are shown in Table II. The amounts of amino groups introduced onto the surface were determined by titration with hydrogen chloride. ${ }^{20}$ The amounts of sodium phenolate and sodium carboxylate groups were estimated from carboxyl and phenolic hydroxyl groups on carbon black, because these acidic groups react quantitatively with sodium hydroxide.
Table II. Contents of functional groups introduced onto the surface of carbon black

\begin{tabular}{|c|c|c|c|}
\hline \multirow{2}{*}{$\mathrm{CB}^{\mathrm{a}}$} & $\mathrm{OH}$ group & $\mathrm{COOH}$ group & Functional group \\
\hline & $\mathrm{mmol} \mathrm{g}^{-1}$ & $\mathrm{mmolg}^{-1}$ & $\mathrm{mmolg}^{-1}$ \\
\hline $\mathrm{CB}-\mathrm{ONa}$ & 0.24 & 0.40 & 0.64 \\
\hline $\mathrm{CB}-\mathrm{NH}_{2}$ & 0.24 & 0.40 & 0.61 \\
\hline
\end{tabular}

${ }^{\text {a }}$ Neospectra II.

Table III. Grafting reactions of carbon black with living poly(IBVE) under various conditions ${ }^{a}$

\begin{tabular}{|c|c|c|c|}
\hline \multirow{2}{*}{ CB } & \multirow{2}{*}{ Poly $(\text { IBVE })^{b}$} & Grafting & $R^{\mathrm{c}}$ \\
\hline & & $\%$ & $\%$ \\
\hline Untreated & Living & Trace & - \\
\hline $\mathrm{CB}-\mathrm{ONa}$ & Quenched & Trace & - \\
\hline $\mathrm{CB}-\mathrm{NH}_{2}$ & Quenched & Trace & - \\
\hline $\mathrm{CB}-\mathrm{ONa}$ & Living & 23.5 & 7.2 \\
\hline $\mathrm{CB}-\mathrm{NH}_{2}$ & Living & 16.2 & 5.3 \\
\hline
\end{tabular}

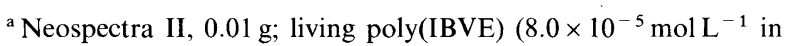
toluene), $10.0 \mathrm{~mL} ; 0{ }^{\circ} \mathrm{C} ; 1 \mathrm{~h} .{ }^{\mathrm{b}} \bar{M}_{n}=5.0 \times 10^{3}\left(\bar{M}_{w} / \bar{M}_{n}=1.10\right)$. ${ }^{\mathrm{c}}$ Percentages of functional groups used for the grafting reaction.

\section{Reaction of Living Poly (IBVE) Cation with $C B-O N a$ and $\mathrm{CB}-\mathrm{NH}_{2}$ \\ Living poly(IBVE) was generated by $\mathrm{CF}_{3} \mathrm{COOH} /$} $\mathrm{ZnCl}_{2}$ initiating system in toluene according to the method of Higashimura and Sawamoto. ${ }^{18,19}$ It was confirmed that the molecular weight distribution was very narrow $\left(M_{w} / M_{n}=1.10\right)$ and the number average molecular weight $\left(M_{n}\right)$ agreed with the theoretical value. The grafting reaction of living poly(IBVE) $\left(M_{n}=5.0 \times\right.$ $10^{3}$ ) with $\mathrm{CB}-\mathrm{NH}_{2}$ or $\mathrm{CB}-\mathrm{ONa}$ derived from Neospectra II was carried out at $0^{\circ} \mathrm{C}$ under several conditions. The results are summarized in Table III.

By the reaction of the untreated carbon black with living poly(IBVE), no grafting onto the carbon black surface was observed. After the quenching of living poly(IBVE) with ammonical methanol, the polymer hardly reacted with $\mathrm{CB}-\mathrm{ONa}$ and $\mathrm{CB}-\mathrm{NH}_{2}$. Poly(IBVE) was found to be grafted onto the carbon black surface when living poly(IBVE) was reacted with $\mathrm{CB}-\mathrm{ONa}$ and $\mathrm{CB}-$ $\mathrm{NH}_{2}$.

The percentages of amino groups and sodium phenolate and carboxylate groups $(R)$ used the grafting reaction with living poly(IBVE) calculated from percentage of grafting and $M_{n}$ of grafted polymer were 5.3 and $7.2 \%$, respectively. This indicates that surface amino groups and sodium phenolate and sodium carboxylate groups are readily blocked by the neighboring grafted polymer chains.

Based on the above results, it is concluded that the living poly(IBVE) cation can be terminated with surface nucleophilic groups of $\mathrm{CB}-\mathrm{ONa}$ and $\mathrm{CB}-\mathrm{NH}_{2}$ of Neospectra II and poly(IBVE) with narrow molecular weight distribution and well defined molecular weight is grafted onto the surface as shown in eq. 1 .

Grafting Reaction of Living Poly(IBVE) Cation with Various Carbon Blacks Having Nucleophilic Groups

Table IV shows the results of the grafting reaction of 
Table IV. Grafting reactions of living poly(IBVE) with various carbon blacks having sodium phenolate groups ${ }^{\mathrm{a}}$

\begin{tabular}{|c|c|c|c|}
\hline \multirow{2}{*}{$\mathrm{CB}$} & \multirow{2}{*}{ Poly(IBVE) ${ }^{b}$} & \multirow{2}{*}{$\frac{\text { Grafting }}{\%}$} & \multirow{2}{*}{$\frac{R^{\mathrm{c}}}{\%}$} \\
\hline & & & \\
\hline \multicolumn{4}{|l|}{ FW 200} \\
\hline Untreated & Living & 8.3 & - \\
\hline $\mathrm{CB}-\mathrm{ONa}$ & Quenched & 6.0 & - \\
\hline $\mathrm{CB}-\mathrm{ONa}$ & Living & 20.2 & 5.6 \\
\hline \multicolumn{4}{|l|}{ Philblack O } \\
\hline Untreated & Living & 4.5 & - \\
\hline $\mathrm{CB}-\mathrm{ONa}$ & Quenched & 3.0 & - \\
\hline $\mathrm{CB}-\mathrm{ONa}$ & Living & 5.7 & 57.0 \\
\hline \multicolumn{4}{|l|}{ Philblack I } \\
\hline Untreated & Living & 5.5 & - \\
\hline $\mathrm{CB}-\mathrm{ONa}$ & Quenched & 3.9 & - \\
\hline $\mathrm{CB}-\mathrm{ONa}$ & Living & 6.3 & 25.2 \\
\hline
\end{tabular}

${ }^{\mathrm{a}} \mathrm{CB}, 0.01 \mathrm{~g}$; living poly(IBVE) $\left(8.0 \times 10^{-5} \mathrm{~mol} \mathrm{~L}^{-1}\right.$ in toluene $)$, $10.0 \mathrm{~mL} ; 00^{\circ} \mathrm{C} ; 1 \mathrm{~h} .{ }^{\circ} \bar{M}_{n}=5.0 \times 10^{3}\left(\bar{M}_{w} / \bar{M}_{n}=1.10\right)$. ${ }^{\mathrm{c}}$ Percentages of functional groups used for the polymerization.

living poly(IBVE) with various carbon blacks having sodium phenolate and sodium carboxylate groups. As well as Neospectra II, it was found that by the reaction of living poly(IBVE) with $\mathrm{CB}-\mathrm{ONa}$, poly(IBVE) with controlled molecular weight and narrow molecular weight distribution can be grafted onto carbon black surface.

The percentage of nucleophilic groups used for the grafting reaction of living poly(IBVE) $(R)$ with Philblack $\mathrm{O}$ and Philblack I with small surface area was larger than that with Neospectra II and FW 200 with large surface area. This suggests that sodium phenolate and sodium carboxylate groups in pore of Neospectra II and FW 200 hardly react with the living polymer cation.

\section{Stability of Grafting Bonds}

By reaction of living poly(IBVE) with surface amino groups, as mentioned above, poly(IBVE) was grafted onto carbon black surface with amino ether bonds considered unstable under acidic conditions. By reaction with $\mathrm{CB}-\mathrm{ONa}$, poly(IBVE) was grafted with acetal bonds, which are also unstable under acidic and basic conditions. Therefore, the stability of the grafting bonds under acidic and basic conditions was examined. ${ }^{14}$ The results are shown in Table V.

Table V clearly shows that even if poly(IBVE)-grafted carbon black obtained from the reaction using $\mathrm{CB}-\mathrm{NH}_{2}$ is treated under basic and acidic conditions, decrease of poly(IBVE) grafting is scarcely observed. This suggests that the amino ether bonds, by which poly(IBVE) is grafted, are stabilized against acidic and basic conditions by neighboring grafted polymer chains on the surface.

When poly(IBVE)-grafted carbon black obtained from the reaction using $\mathrm{CB}-\mathrm{ONa}$ was treated with aqueous alkali and acid, grafted poly(IBVE) was removed from the surface (Table VI). This indicates that acetal bonds are readily hydrolyzed under acidic and basic conditions.

\section{Effects of Molecular Weight of Living Polymer on Grafting}

The effects of molecular weight of living poly(IBVE) on the grafting reaction with $\mathrm{CB}-\mathrm{NH}_{2}$ and $\mathrm{CB}-\mathrm{ONa}$
Table V. Effects of acid and alkali treatment on the hydrolysis of amino ether bonds with which poly(IBVE) is grafted ${ }^{\mathrm{a}}$

\begin{tabular}{cccc}
\hline \multirow{2}{*}{ Treatment } & \multicolumn{2}{c}{ Grafting/\% } & \multirow{2}{*}{ Weight loss } \\
\cline { 2 - 3 } & $\begin{array}{c}\text { Before } \\
\text { treatment }\end{array}$ & $\begin{array}{c}\text { After } \\
\text { treatment }\end{array}$ & $\%$ \\
\hline Water & 15.1 & 15.1 & \\
$17.5 \% \mathrm{HCl}$ aq. soln. & 15.9 & 15.2 & \\
$10.0 \% \mathrm{NaOH}$ aq. soln. & 14.6 & 13.8 & \\
\hline
\end{tabular}

a Poly(IBVE)-grafted $\mathrm{CB}, 0.10 \mathrm{~g}, \mathrm{HCl}$ (or $\mathrm{NaOH}$ ) aq. solution, $10.0 \mathrm{~mL}$; room temperature, $30 \mathrm{~min}$.

Table VI. Effects of acid and alkali treatment on the hydrolysis of acetal bonds with which poly(IBVE) is grafted $^{\mathrm{a}}$

\begin{tabular}{ccccc}
\hline \multirow{2}{*}{ Treatment } & \multicolumn{2}{c}{ Grafting/\% } & \multirow{2}{*}{ Weight loss } \\
\cline { 2 - 3 } \cline { 5 - 5 } $\begin{array}{c}\text { Before } \\
\text { treatment }\end{array}$ & $\begin{array}{c}\text { After } \\
\text { treatment }\end{array}$ & $\%$ \\
\hline Water & 18.9 & 18.9 & 0 \\
$17.5 \% \mathrm{HCl}$ aq. soln. & 19.7 & 11.8 & 40.1 \\
$10.0 \% \mathrm{NaOH}$ aq. soln. & 20.1 & 14.1 & 29.9 \\
\hline
\end{tabular}

${ }^{\text {a }}$ Poly(IBVE)-grafted $\mathrm{CB}, 0.10 \mathrm{~g}, \mathrm{HCl}$ (or $\mathrm{NaOH}$ ) aq. solution, $10.0 \mathrm{~mL}$; room temperature, $30 \mathrm{~min}$.

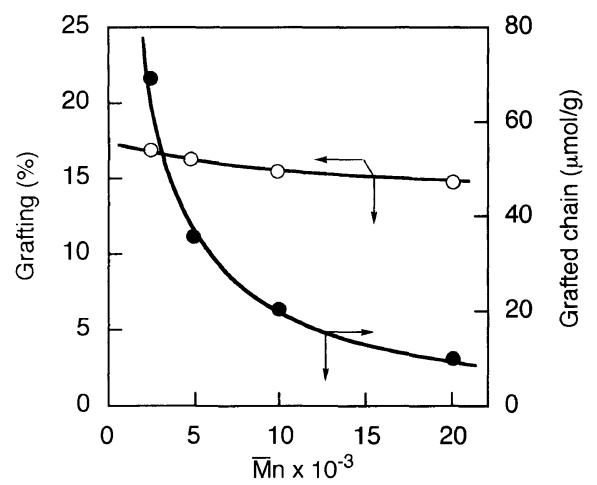

Figure 1. Effects of molecular weight of living poly(IBVE) on grafting onto $\mathrm{CB}-\mathrm{NH}_{2}$. Neospectra II, $0.01 \mathrm{~g}$; living poly(IBVE) $(8.0 \times$ $10^{-5} \mathrm{~mol} \mathrm{~L}^{-1}$ in toluene), $10.0 \mathrm{~mL} ; 0^{\circ} \mathrm{C} ; 1 \mathrm{~h}$.

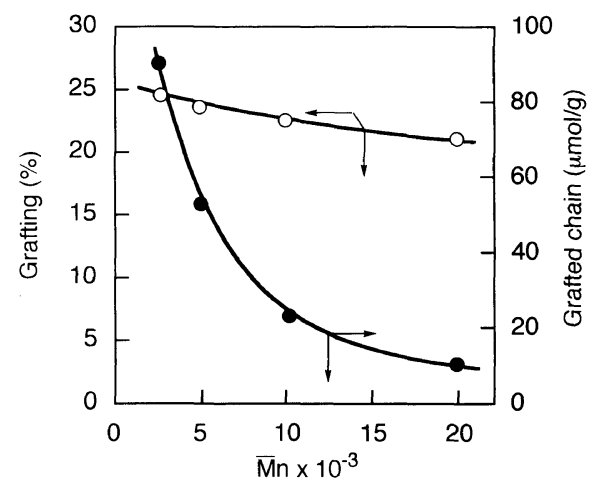

Figure 2. Effects of molecular weight of living poly(IBVE) on grafting onto CB ONa. Neospectra II, $0.01 \mathrm{~g}$; living poly(IBVE) $(8.0 \times$ $10^{-5} \mathrm{~mol} \mathrm{~L}^{-1}$ in toluene), $10.0 \mathrm{~mL} ; 0^{\circ} \mathrm{C} ; 1 \mathrm{~h}$.

were examined. The results are shown in Figures 1 and 2.

It is of interest to note that the percentage of grafting and number of grafted chains decreased with increasing molecular weight of the living polymer cation. This was observed in the grafting reaction of surface reactive 
Table VII. Grafting reactions of living poly(MeOZO) with carbon black having functional groups ${ }^{\mathrm{a}}$

\begin{tabular}{|c|c|c|c|c|}
\hline \multirow{2}{*}{ Carbon black } & \multirow{2}{*}{$\bar{M}_{n} \times 10^{-3}$} & \multirow{2}{*}{$\frac{\text { Grafting }}{\%}$} & \multirow{2}{*}{$\frac{\begin{array}{c}\text { Polymer } \\
\text { grafted }\end{array}}{\mathrm{mg} \mathrm{m}^{-2}}$} & \multirow{2}{*}{$\begin{array}{c}\begin{array}{c}\text { Grafted } \\
\text { chain }\end{array} \\
\mu \mathrm{mol} \mathrm{g}^{-1}\end{array}$} \\
\hline & & & & \\
\hline $\mathrm{CB}-\mathrm{ONa}$ & 2.2 & 31.8 & 0.35 & 144.5 \\
\hline $\mathrm{CB}-\mathrm{ONa}$ & 4.4 & 28.9 & 0.32 & 65.6 \\
\hline $\mathrm{CB}-\mathrm{ONa}$ & 8.8 & 28.1 & 0.31 & 31.9 \\
\hline $\mathrm{CB}-\mathrm{NH}_{2}$ & 2.2 & 32.9 & 0.36 & 149.5 \\
\hline $\mathrm{CB}-\mathrm{NH}_{2}$ & 4.4 & 25.5 & 0.28 & 56.0 \\
\hline $\mathrm{CB}-\mathrm{NH}_{2}$ & 8.8 & 24.8 & 0.27 & 28.2 \\
\hline
\end{tabular}

${ }^{\mathrm{a}}$ Neospectra II, $0.01 \mathrm{~g}$; living poly(MeOZO) $\left(0.25 \mathrm{~mol} \mathrm{~L}^{-1}\right.$ in acetonitrile), $26.0 \mathrm{~mL} ; 80^{\circ} \mathrm{C} ; 20 \mathrm{~h}$.

groups on carbon black with amino- or hydroxyl-terminated functional polymers ${ }^{11}$ and in the grafting by the termination of living polymer cation with amino groups on silica. ${ }^{14}$

This may be due to the fact that the surface nucleophilic groups on carbon black are shielded by neighboring grafted polymer chains. This effect on the grafting was enhanced with increase in molecular weight of the living polymer.

\section{Grafting of Living Poly(MeOZO) onto Carbon Black Surface}

The living poly(MeOZO) cation is also very sensitive to nucleophiles such as amines. ${ }^{25}$ Therefore, the grafting of poly(MeOZO) onto carbon black surface by termination of the living poly $(\mathrm{MeOZO})$ cation with $\mathrm{CB}-\mathrm{NH}_{2}$ and $\mathrm{CB}-\mathrm{ONa}$ (eq 2) was examined. Table VII shows the results of the grafting reactions of $\mathrm{CB}-\mathrm{NH}_{2}$ and $\mathrm{CB}-\mathrm{ONa}$ with living poly(MeOZO) generated by the ring-opening polymerization of MeOZO using MeOTs as a catalyst.

By the reaction of living poly(MeOZO) cation with $\mathrm{CB}-\mathrm{NH}_{2}$ and $\mathrm{CB}-\mathrm{ONa}$, poly(MeOZO) with controlled molecular weight and narrow molecular weight distribution could be grafted onto the surface. As well as poly(IBVE) grafting, the percentage of poly(MeOZO) grafting and number of grafted poly(MeOZO) chains decreased with increasing molecular weight of living poly(MeOZO) cation.

\section{Dispersibility of Polymer-Grafted Carbon Black}

The dispersibility of poly(MeOZO)-grafted carbon black in methanol and benzene was compared with that of untreated carbon black in methanol. The results are shown in Figure 3. Untreated carbon black completely precipitated after 1 day. Poly(MeOZO)-grafted carbon black was found to produce stable colloidal dispersions in both methanol and benzene. This suggests that poly(MeOZO) chains are grafted onto the surface interfere with aggregation of carbon black in both hydrophobic and hydrophilic solvents. Accordingly, the dispersibility of carbon black in organic solvents was remarkably improved by the grafting of poly(MeOZO) onto the surface.

\section{Effects of Molecular Weight of Grafted Polymer on the Dispersibility of Carbon Black \\ Using two kinds of poly(IBVE)-grafted carbon blacks}

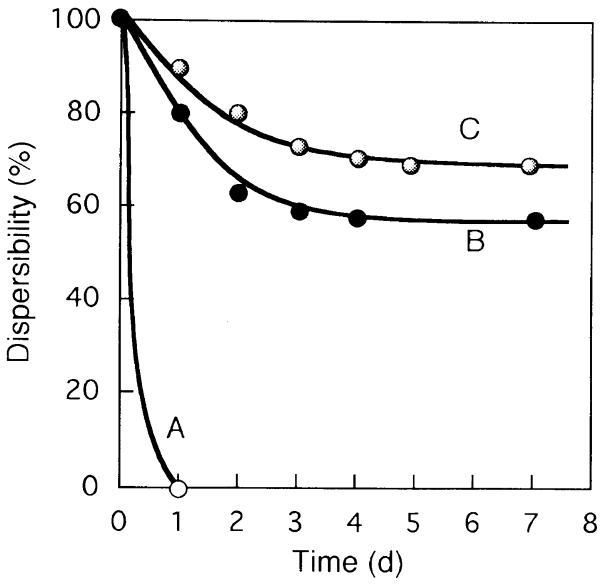

Figure 3. Stability of dispersion of (A) untreated carbon black in methanol, (B) poly(MeOZO)-grafted carbon black in benzene, and (C) poly(MeOZO)-grafted carbon black in methanol.

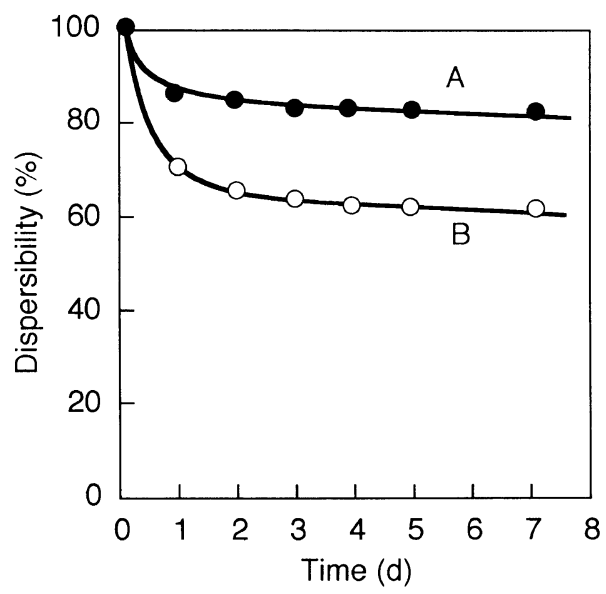

Figure 4. Effects of molecular weight on the stability of the dispersion of poly(MeOZO)-grafted carbon black in methanol. (A) Grafting = $27.1 \%, M_{n}=1.0 \times 10^{4}$, grafted polymer $=2.7 \times 10^{-5} \mathrm{~mol} \mathrm{~g}^{-1}$. (B) Grafting $=30.1 \%, M_{n}=2.2 \times 10^{3}$, grafted polymer $=13.7 \times 10^{-5} \mathrm{~mol} \mathrm{~g}^{-1}$.

with almost same percentage of grafting but different molecular weight, the effects of molecular weight of grafted poly(IBVE) on the dispersibility in methanol were investigated. The results are shown in Figure 4. The dispersibility of poly(MeOZO)-grafted carbon black was affected by the molecular weight of the grafted chain. The number of grafted polymer chains was small, but poly(IBVE)-grafted carbon black with long polymer chains gave a more stable dispersion in methanol than with short polymer chains.

\section{CONCLUSIONS}

1. Poly(IBVE) and poly(MeOZO) with controlled molecular weight and narrow molecular weight distribution were readily grafted onto carbon black surface by termination of the corresponding living polymer cation with nucleophilic groups introduced onto the surface.

2. Percentages of grafting of polymers onto the surface decreased with increasing molecular weight of living polymer cation.

3. Polymer-grafted carbon black gave a stable colloidal dispersion in a good solvent of grafted chains. Surface grafted polymer with high molecular weight is 
more effective than that with low molecular weight for improvement of dispersibility of carbon black.

\section{REFERENCES}

1. N. Tsubokawa and T. Endo, Tanso, No. 140, 322 (1989).

2. N. Tsubokawa, Hyomen, 28, 286 (1990).

3. N. Tsubokawa, Prog. Polym. Sci., 17, 417 (1992).

4. N. Tsubokawa, A. Funaki, Y. Hada, and Y. Sone, J. Polym. Sci. Polym. Chem. Ed., 20, 3297 (1987).

5. N. Tsubokawa, A. Yamada, and Y. Sone, Polym. Bull., 10, 62 (1983).

6. N. Tsubokawa, J. Polym. Sci., Polym. Chem. Ed., 21, 705(1983).

7. N. Tsubokawa and S. Handa, J. Macromol. Sci., Pure Appl. Chem., A30, 277 (1993).

8. N. Tsubokawa, K. Fujiki, and Y. Sone, Polym. J., 20, 213 (1988).

9. K. Fujiki, N. Tsubokawa, and Y. Sone, Polym. J., 22, 661 (1990).

10. N. Tsubokawa, Y. Shirai, and K. Hashimoto, Colloid Polym. Sci., 293, 1049 (1995).

11. N. Tsubokawa, Nippon Kagaku Kaishi, 1012 (1993).

12. E. Papirer and N. Tao, J. Polym. Sci., Polym. Lett. Ed., 9, 195 (1971).

13. E. Papirer, N. Tao, and J. B. Donnet, Angew. Makromol. Chem.,
19, 65 (1971).

14. N. Tsubokawa and S. Yoshikawa, J. Polym. Sci., Part A: Polym. Chem., 33, 581 (1995)

15. N. Tsubokawa and H. Tsuchida, J. Macromol. Sci., Pure Appl. Chem., A29, 311 (1992)

16. N. Tsubokawa, K. Magara, and Y. Sone, Nippon Gomu Kyokaishi, 64, 378 (1991)

17. N. Tsubokawa, K. Kobayashi, and Y. Sone, Polym. J., 19, 1147 (1987).

18. K. Kamigaito, M. Sawamoto, and T. Higashimura, Macromolecules, 24, 3988 (1991).

19. M. Kamigaito, K. Yamaoka, M. Sawamoto, and T. Higashimura, Macromolecules, 25, 6400 (1992).

20. T. Saegusa, H. Ikeda, and H. Fujiki, Macromolecules, 5, 359 (1972).

21. T. Saegusa and H. Ikeda, Macromolecules, 6, 808 (1973).

22. M. Sawamoto, T. Enoki, and T. Higashimura, Macromolecules, 20, 1 (1987).

23. M. Sawamoto, T. Enoki, and T. Higashimura, Macromolecules, 18, 123 (1985).

24. M. Sawamoto, T. Enoki, and T. Higashimura, Polym. Bull., 18, 117 (1987).

25. S. Kobayashi, M. Kaku, S. Sawada, and T. Saegusa, Polym. Bull., 13, 447 (1985) 